\title{
Glycogen and poly- $\beta$-hydroxybutyrate synthesis in Spirulina maxima
}

\author{
Roberto De Philippis, Claudio Sili and Massimo Vincenzini*
}

Dipartimento di Scienze e Tecnologie Alimentari e Microbiologiche, Sez. Microbiologia Applicata, Università, and Centro di Studio dei Microrganismi Autotrofi, CNR, Piazzale delle Cascine 27, I-50144 Firenze, Italy

(Received 30 December 1991; revised 30 March 1992; accepted 27 April 1992)

\begin{abstract}
The effect of different growth conditions on the glycogen and poly- $\beta$-hydroxybutyrate (PHB) content of the cyanobacterium Spirulina maxima is described. Under photoautotrophic growth conditions without any nutrient limitation, $S$. maxima exhibited a glycogen content of between $7 \cdot 1$ and $10.7 \%$ of cell dry wt, whereas PHB was undetectable. When $S$. maxima was grown under mixotrophic conditions in the presence of acetate, the intracellular PHB concentration increased to more than $3 \%$ of dry wt, while glycogen content remained within the range of 5 to $6 \%$ of cell dry wt. Nitrogen starvation favoured glycogen accumulation (up to 60 to $70 \%$ of dry wt), while the PHB content remained low (up to $0.7 \%$ of dry wt), even after prolonged nitrogen starvation. Inhibition of protein synthesis, induced by addition of azaserine, led to the accumulation of glycogen (up to $52 \%$ of cell dry wt) but did not stimulate PHB synthesis. Under phosphorus-limited growth conditions, glycogen and PHB accumulated (up to $23 \%$ and $1 \cdot 2 \%$ of cell dry wt, respectively) only after the exhaustion of intracellular phosphorus reserves. Shifting the culture from low to high light irradiance induced a rapid accumulation of glycogen (up to $34 \%$ of cell dry wt after $9 \mathrm{~h}$ ) but did not induce PHB synthesis. Results are discussed in terms of the metabolic significance of PHB synthesis in cyanobacteria, and suggest that this polymer acts exclusively as a disposal mechanism to eliminate excess reducing equivalents.
\end{abstract}

\section{Introduction}

The major carbon- and energy-reserve compound accumulated by cyanobacteria during photoautotrophic growth is generally a glycogen-like polyglucan (Smith, 1982; Allen, 1984; Jensen, 1985; Shively, 1988). This polymer is massively accumulated in cyanobacterial cells whenever balanced growth is hampered by a particular nutrient deficiency (Allen \& Smith, 1969; Lehmann \& Wöber, 1976; van Eykelenburg, 1980; Stevens et al., 1981 ) or by sudden increases in energy input (Ernst \& Böger, 1985; Post, 1987). Once conditions for balanced growth are re-established, accumulated glycogen is rapidly broken down to yield energy and carbon for cell metabolism. It has therefore been suggested that glycogen acts as a dynamic reserve with the dual function of storage product and of buffer substance able to separate the process of carbon supply from its subsequent utilization in other biosynthetic pathways (Carr, 1988). In a few instances the presence of poly- $\beta$ hydroxybutyrate (PHB), a widespread intracellular stor-

\footnotetext{
* Author for correspondence. Tel. 55-360506; fax 55-330431.
}

Abbreviations: Chl $a$, chlorophyll $a$; PHB, poly- $\beta$-hydroxybutyrate. age compound typical of prokaryotic organisms, has also been reported in cyanobacteria. However, with the sole exception of a Spirulina platensis strain, for which a PHB content of $6 \%$ of cell dry wt has been reported (Campbell et al., 1982), in those cyanobacterial strains so far investigated PHB was found at concentrations never exceeding a few milligrams per g dry wt (Carr, 1966; Capon et al., 1983; Vincenzini et al., 1990). The occurrence of PHB in a group of micro-organisms that lacks a complete tricarboxylic acid cycle is very intriguing since the breakdown of this reserve polymer can play only a minor role in cell metabolism, because the acetyl-CoA which arises from its depolymerization can be utilized neither for significant energy production nor for the synthesis of more than a few cell constituents (Smith, 1982). Consequently, the role of PHB in cyanobacterial metabolism is still unclear, and it is not known which, if any, growth conditions induce or stimulate the synthesis of the polymer in cultures growing photoautotrophically. Moreover, it remains controversial whether mixotrophic growth in the presence of acetate actually affects PHB accumulation in cyanobacteria since in some strains the addition of acetate has a stimulatory effect on PHB synthesis (Carr, 1966; Allen, 1984; Vincenzini et al., 1990), whereas in 
others it neither induces (Ihlenfeldt \& Gibson, 1977; Allen, 1984) nor enhances (Campbell et al., 1982) PHB accumulation.

No data are available on the possible simultaneous accumulation of PHB and glycogen in cyanobacteria. We present here the results of a study of the effect in Spirulina maxima of conditions known to stimulate the accumulation of these carbon reserves in a range of micro-organisms (Dawes \& Senior, 1973; Dawes, 1986; Preiss \& Romeo, 1989; Anderson \& Dawes, 1990). The influence of acetate on the synthesis of these macromolecular compounds in mixotrophically growing $S$. maxima is also reported.

\section{Methods}

\begin{abstract}
Organism and culture conditions. Spirulina maxima strain SOSA 18 (culture collection of the Centro di Studio dei Microrganismi Autotrofi) was grown on standard mineral medium (Bocci et al., 1987) at $30^{\circ} \mathrm{C}$ in batch cultures continuously illuminated with cool-white fluorescent lamps giving a mean photosynthetic photon flux density of $50 \mu \mathrm{mol}$ $\mathrm{m}^{-2} \mathrm{~s}^{-1}$ at the culture surface. Pure $\mathrm{CO}_{2}$ was bubbled into the cultures in order to maintain the $\mathrm{pH}$ level between $9 \cdot 3$ and $9 \cdot 6$. Nitrogen- or phosphorus-starved cultures were obtained by adding centrifuged and washed trichomes, taken from stock cultures grown on standard mineral medium, into media prepared without addition of $\mathrm{KNO}_{3}$ or $\mathrm{K}_{2} \mathrm{HPO}_{4}$ respectively. When required, azaserine (from Sigma), an inhibitor of glutamine-amine transferases such as GOGAT (glutamate synthase), was added to the standard mineral medium to bring the final concentration up to $0.85 \mathrm{~mm}$. The shift to a higher light irradiance was achieved through a sudden increase in the mean photosynthetic flux density from 50 to $440 \mu \mathrm{mol} \mathrm{m} \mathrm{m}^{-2} \mathrm{~s}^{-1}$. Mixotrophic growth conditions were obtained by adding sodium acetate (to a final concentration of $8.7 \mathrm{~mm}$ ) to the standard mineral medium, without changing the other culture parameters. The purity of the cultures was tested following Rippka et al. (1979).
\end{abstract}

Analytical procedures. Cell dry wt was determined in duplicate on $10 \mathrm{ml}$ culture samples. After filtration through $8 \mu \mathrm{m}$ membranes, the cells were washed twice with distilled water and dried at $105^{\circ} \mathrm{C}$ for $3 \mathrm{~h}$. Chlorophyll $a(\mathrm{Chl} a)$ content of the cultures was determined spectrophotometrically in $90 \%(\mathrm{v} / \mathrm{v})$ acetone extracts following Parson \& Strickland (1963). Phycobiliproteins were extracted from the cells and measured in crude extracts following Bennet \& Bogorad (1973). Glycogen was extracted from trichomes according to the procedure described by Ernst $e$ t al. (1984) and estimated by the phenol/sulphuric acid method (Dubois et al., 1956), glucose being used as a standard.

For PHB determinations, 5-10 ml of culture suspension were filtered through a Whatman GF/F glassfibre disk and digested according to Karr et al. (1983). This treatment converts PHB into crotonic acid, which was assayed by HPLC. The latter was done using a model 342 gradient chromatograph (Beckman) provided with a model 165 variable wavelength detector and a computerized system for pump control and data elaboration (System Gold, Beckman). Crotonic acid was eluted from an Ultrasphere ODS C-18 column $(250 \times 4.6 \mathrm{~mm}$ i.d.) preceded by an ODS C-18 guard column $(20 \times 4.6 \mathrm{~mm}$ i.d.; Supelco). A mobile phase comprising $15 \%(\mathrm{v} / \mathrm{v})$ acetonitrile in $0 \cdot 1 \%(\mathrm{v} / \mathrm{v}) \mathrm{H}_{3} \mathrm{PO}_{4}$ in aqueous solution was employed at a flow rate of $1.5 \mathrm{ml} \mathrm{min}^{-1}$. Under these conditions the retention time of crotonic acid, detected at $214 \mathrm{~nm}$, was $7.4 \mathrm{~min}$. Peak areas were compared to a calibration curve; the detection limit of crotonic acid was calculated to correspond to $0.05 \mathrm{mg}$ PHB per litre of culture.
For acetate determinations, $1-2 \mathrm{ml}$ of culture suspension were filtered through $0 \cdot 8 \mu \mathrm{m}$ membranes and the resulting cell-free medium was assayed for acetic acid by HPLC under the same conditions as for assay of PHB. The retention time of acetic acid, detected at $214 \mathrm{~nm}$, was $2.9 \mathrm{~min}$.

Photosynthetic photon flux densities at the culture surfaces were determined with a quantum/radiometer/photometer model LI-185 B equipped with a quantum sensor model LI-190 SB (LI-COR Ltd, USA).

Photosynthetic oxygen evolution was determined at $30^{\circ} \mathrm{C}$ under saturating light conditions with a Clark-type electrode (Yellow Springs Instruments, USA).

\section{Results}

\section{Photoautotrophic growth}

The behaviour of Spirulina maxima during photoautotrophic growth on the standard mineral medium (control culture) is represented in Fig. 1. Under the experimental conditions used, a final cell concentration of $1260 \mathrm{mg}$ dry wt $1^{-1}$ was reached with a cell yield (i.e. final minus initial cell concentration) of $880 \mathrm{mg} \mathrm{l}^{-1}$ at the end of the culture period. The low growth rates shown by this culture, below the maximum attainable by the strain, were exclusively due to the low light intensity used. During growth, the intracellular glycogen content ranged from $7 \cdot 1$ to $10.7 \%$ of dry wt, with the highest values occurring toward the end of the culture period. On the other hand, no trace of PHB was revealed by HPLC analyses of the culture samples taken at various stages of growth (Fig. 1).

\section{Mixotrophic growth}

Addition of acetate to the growth medium of $S$. maxima caused two main differences in the behaviour of the culture with respect to that of the control: (i) the final cell yield was significantly higher (about $28 \%$ ), and (ii) PHB was found in all the culture samples (Fig. 2). The positive effect of acetate on cell yield only became evident in the last $2 \mathrm{~d}$ of cultivation, even though it was metabolized throughout the growth period. The resulting decrease in acetate concentration from 8.7 to $1.9 \mathrm{~mm}$ fully justifies, in terms of mass balance, the higher cell yield found in this culture. As has been observed in other cyanobacteria growing on acetate (Pearce \& Carr, 1967), the assimilation of acetate did not modify photosynthetic or respiratory activities: both photoautotrophic and mixotrophic cultures showed an oxygen evolution rate which remained between 4.0 and $4.5 \mu \mathrm{mol} \mathrm{O}_{2} \mathrm{~min}^{-1}(\mathrm{mg} \mathrm{Chl}$ $a)^{-1}$ and a dark oxygen uptake of 0.20 to $0.25 \mu \mathrm{mol}$ $\mathrm{O}_{2} \min ^{-1}(\mathrm{mg} \mathrm{Chl} a)^{-1}$ (data not shown). The glycogen content of the culture showed a linear increase throughout the growth period (Fig. 2), but the intracellular glycogen content remained between 4.6 and $5.2 \%$ of cell 


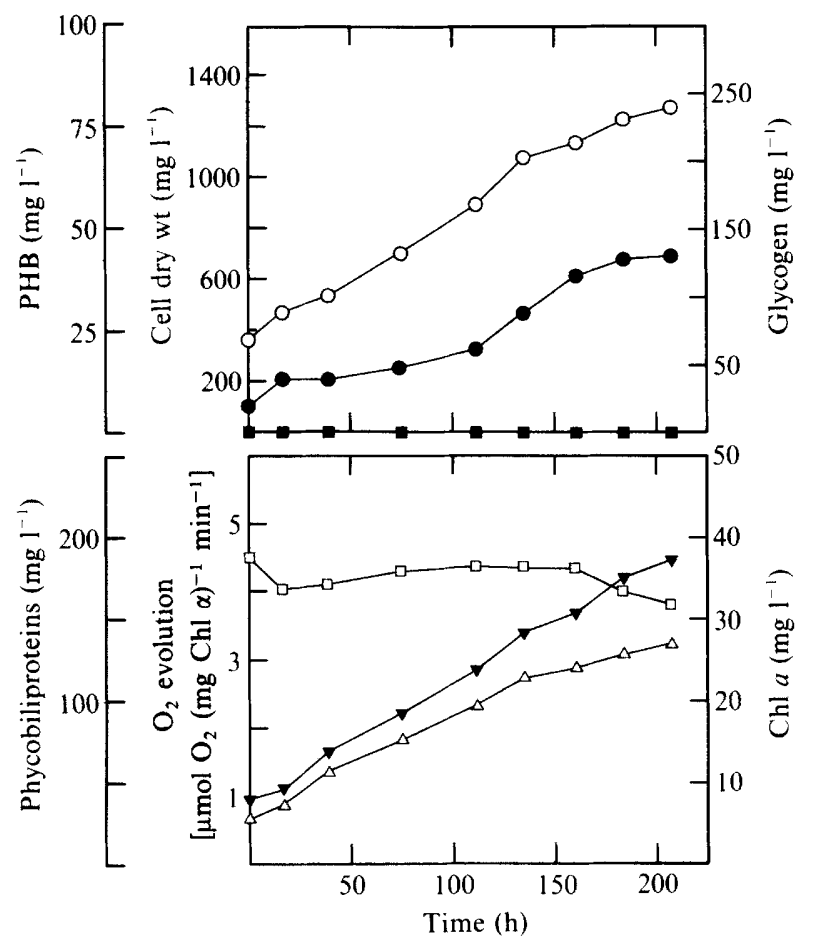

Fig. 1
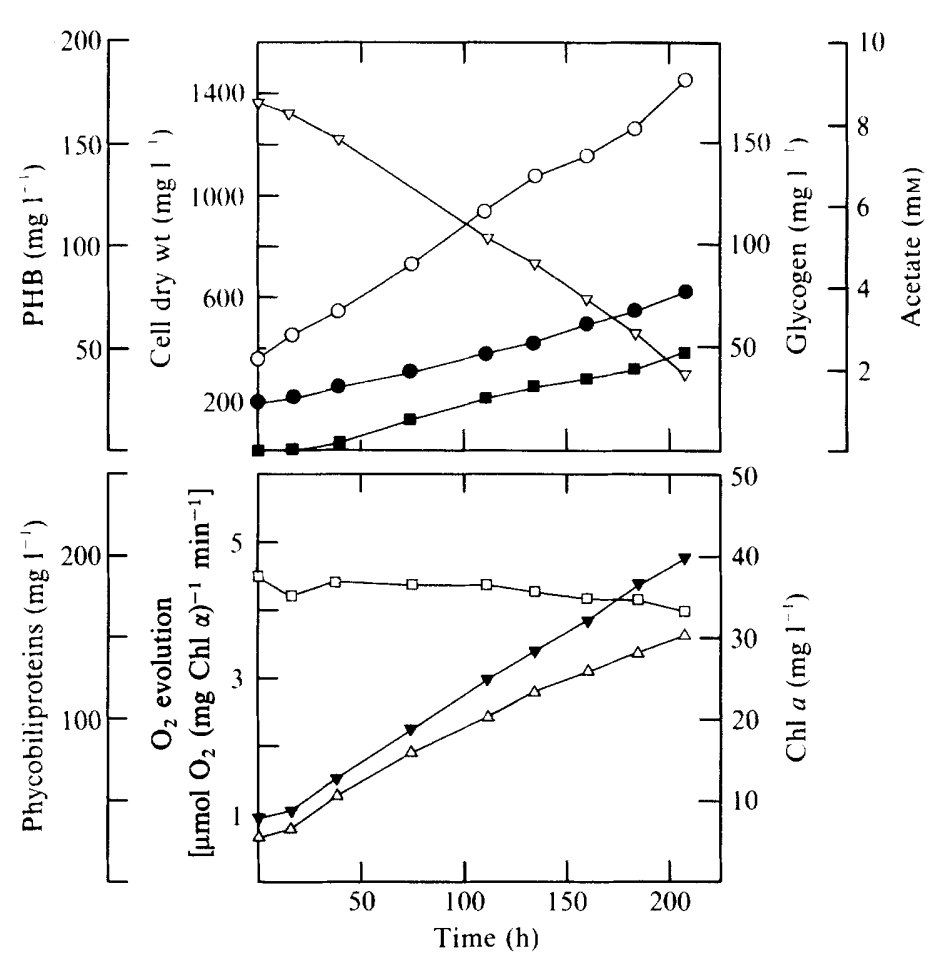

Fig. 2

Fig. 1. Cellular parameters associated with photoautotrophic growth of $S$. maxima in standard mineral medium. $O$, Cell dry wt; $\square$, PHB ;, glycogen; $\square$, photosynthetic oxygen evolution; $\nabla$, phycobiliproteins; $\triangle$, Chl $a$.

Fig. 2. Cellular parameters associated with mixotrophic growth of $S$. maxima in the presence of acetate (8.7 mM initial concentration). $O$, Cell dry wt;, PHB; , glycogen; $\nabla$, acetate concentration; $\square$, photosynthetic oxygen evolution; $\nabla$, phycobiliproteins; $\triangle$, Chl $a$.

dry wt. These values, slightly lower than those of the control culture, demonstrate that acetate does not affect glycogen accumulation in S. maxima. On the other hand, the presence of acetate in the medium strongly affected PHB synthesis: traces of PHB were found $17 \mathrm{~h}$ after inoculation; thereafter its concentration in the culture increased linearly with a mean rate of synthesis as high as that for glycogen (Fig. 2). At the end of the culture period, the intracellular PHB level reached $3.1 \%$ of dry wt. When the acetate in the medium was exhausted, an immediate and regular decrease in the intracellular PHB content was observed, and total breakdown of PHB occurred within a few days without influencing the glycogen content of the cells (data not shown).

\section{Nitrogen-limited growth}

When $S$. maxima was transferred into a culture medium devoid of a nitrogen source, cell growth, that is the balanced increase of all cell constituents, ceased within a few hours, although metabolic activities persisted throughout the cultivation period (Fig. 3). In accordance with the general response of cyanobacteria to nitrogen starvation (Allen, 1984; Carr, 1988), S. maxima under- went a marked change in pigmentation mainly due to the cessation of $\mathrm{Chl} a$ synthesis and to the progressive loss of phycobiliproteins (from 33.4 to $17.7 \mathrm{mg} \mathrm{1}^{-1}$ ). Moreover, owing to the persistence of photosynthetic activity, glycogen accumulated, accounting for almost all the observed increases in cell dry wt and reaching an intracellular concentration of about $70 \%$ of dry wt $163 \mathrm{~h}$ after the transfer to nitrogen-free medium. In the $48 \mathrm{~h}$ following this peak, glycogen was actively broken down, and its concentration dropped to $54 \%$ of dry wt, while the cell dry wt itself showed a slight increase, since a proportion of the initial photosynthetic activity persisted.

The data reported in Fig. 3 clearly show that PHB synthesis occurred only after $4 \mathrm{~d}$ of nitrogen starvation, so that a direct effect of nitrogen depletion may be excluded. The intracellular concentration of PHB never exceeded $0.7 \%$ of dry wt and did not change during the phase of glycogen degradation, so that a strict relationship between the two polymers may also be excluded. However, synthesis of PHB undoubtedly occurred when the physiological status of the trichomes was far from optimal.

When nitrogen starvation was induced by adding 


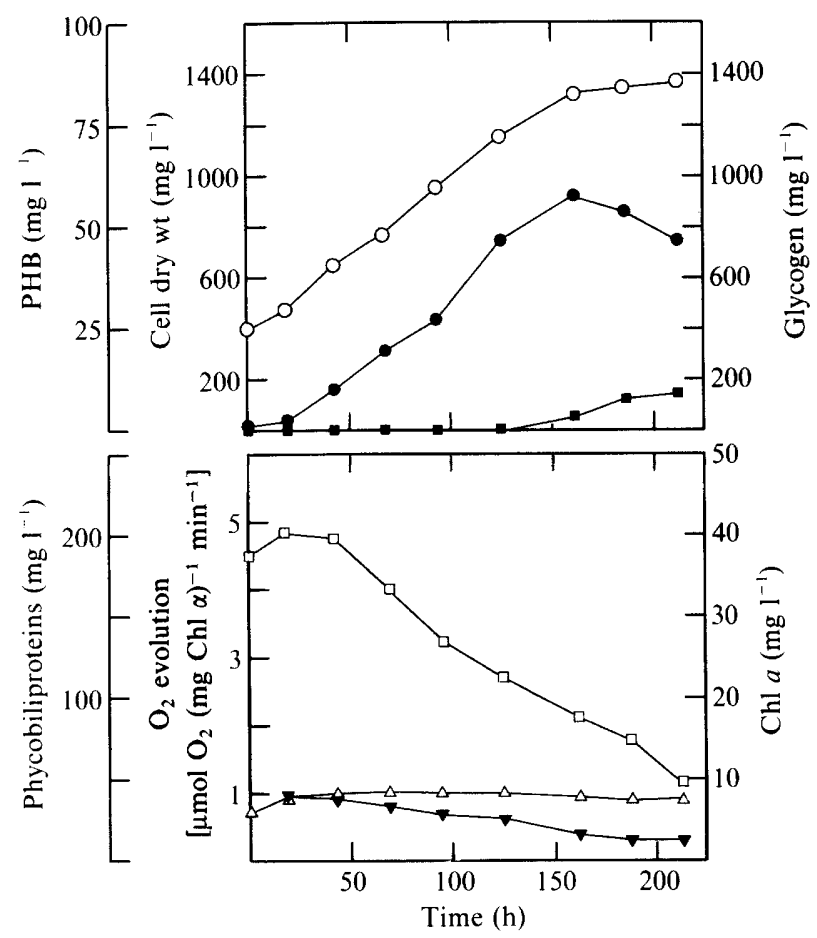

Fig. 3

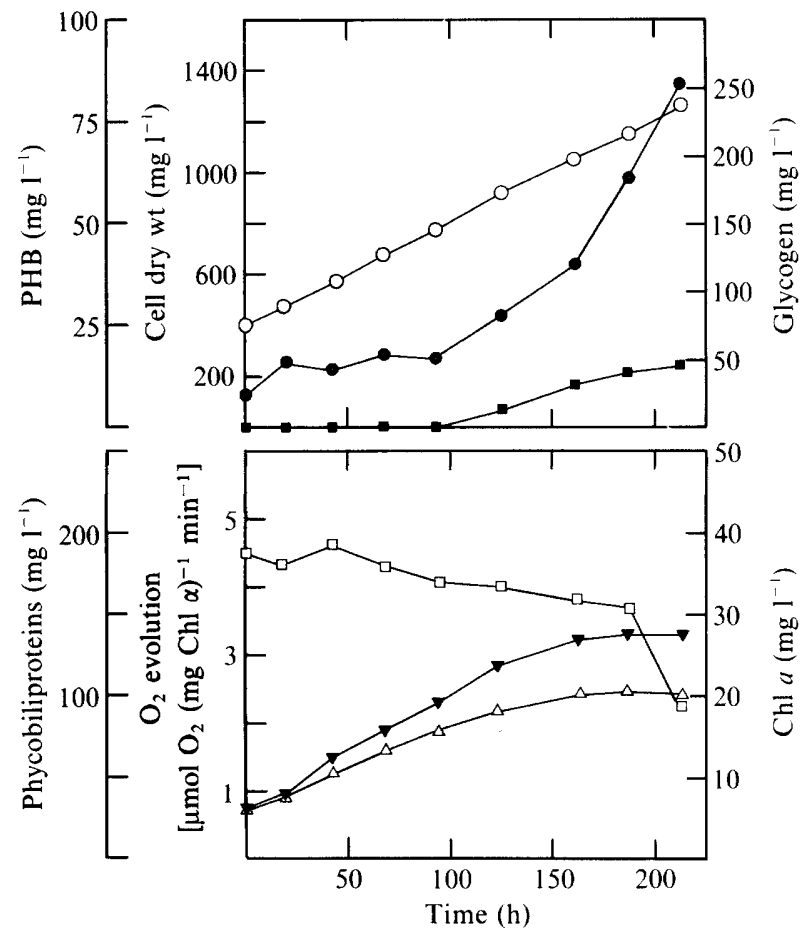

Fig. 4

Fig. 3. Cellular parameters associated with photoautotrophic growth of $S$. maxima transferred from a medium with, to a medium without, fixed nitrogen. $\bigcirc$, Cell dry wt; $\square$, PHB; , glycogen; $\square$, photosynthetic oxygen evolution; $\nabla$, phycobiliproteins; $\triangle$, Chl $a$. Note that the glycogen scale is 16 times higher than the PHB scale.

Fig. 4. Cellular parameters associated with photoautotrophic growth of $S$. maxima transferred from a medium with, to a medium without, phosphorus. $\mathrm{O}$, Cell dry wt; $\square$, PHB; , glycogen; $\square$, photosynthetic oxygen evolution; $\nabla$, phycobiliproteins; $\triangle$, Chl $a$. Note that the glycogen scale is 3.0 times higher than the PHB scale.

azaserine, thus inhibiting nitrogen incorporation without interfering with nitrate reduction, the response of the strain was the same as in the previous case: glycogen accumulated to an intracellular concentration of about $52 \%$ of dry wt after $72 \mathrm{~h}$ (data not shown). Unfortunately, in this experiment the trichomes formed clumps and there was a rapid drop in photosynthetic activity (data not shown) which prevented the continuation of the experiment. Nevertheless, PHB was not found, demonstrating that the polymer is not synthesized by nitrogenstarved trichomes if nitrate reduction is allowed to compete for reducing power.

\section{Phosphorus-limited growth}

The growth of $S$. maxima in mineral medium devoid of any phosphorus source was similar to that of the control culture for at least $100 \mathrm{~h}$ (Fig. 4). Balanced growth was probably supported by the intracellular polyphosphate reserves. Following this period the culture became starved of phosphorus, indicated by the progressive decrease in pigment content in comparison to the control culture (Fig. 4). In this phosphorus-limited growth phase glycogen accumulated, reaching an intracellular concentration of about $23 \%$ from an initial value of about $8 \%$ of dry wt. However, the rate of glycogen accumulation during phosphorus starvation was not so high as under nitrogen starvation, and accounted for most, but not all, of the increase in the cell dry wt of the culture. Synthesis of PHB was also observed (Fig. 4), so that its concentration rose rapidly from values below the detection limit to about $1.2 \%$ of cell dry wt. The two polymers were synthesized at quite different rates, the mean rate of PHB synthesis being at least 20 times lower than that of glycogen.

\section{Shift to high light irradiance}

Rapid changes in light irradiance are known to have powerful effects on the carbon/nitrogen ratio of photosynthetically growing cyanobacterial cells. A shift from low to high irradiance, in particular, is known to cause an immediate increase in photosynthetic activity and growth rate and to induce an initial accumulation of carbohydrates without interfering with nitrogen metabolism (Ernst \& Böger, 1985; Post, 1987; Vincenzini et al., 


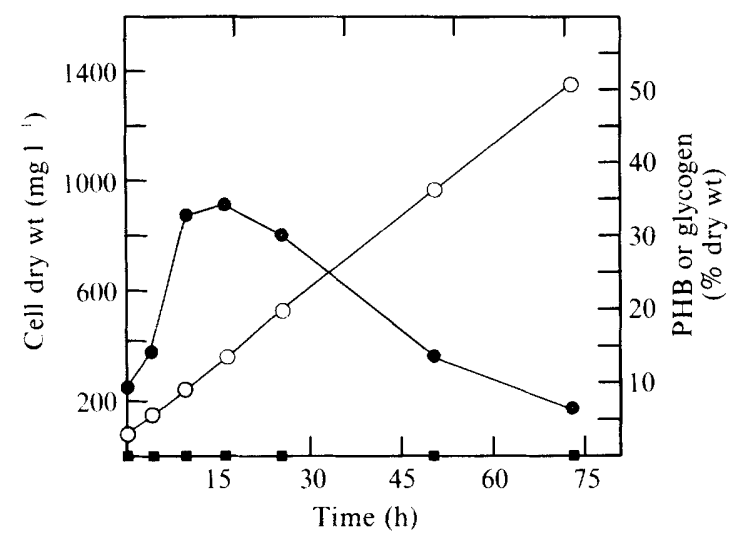

Fig. 5. Cellular parameters associated with photoautotrophic growth of $S$. maxima shifted to higher light irradiance (from 50 to $440 \mu \mathrm{mol}$ $\mathrm{m}^{-2} \mathrm{~s}^{-1}$ ). O, Cell dry wt; $\mathbf{\square}$, PHB;, glycogen.

1989). The response of $S$. maxima to a rapid shift from low to high irradiance was consistent with this model: on a dry wt basis, the glycogen content changed very quickly, rising from an initial value of about $8 \%$ to about $34 \%$ within a period of only $9 \mathrm{~h}$ from the transition (Fig.5). In contrast, there was no immediate effect on PHB, which remained below the detection limit. This situation did not change even during the post-adaption phase, when the glycogen concentration in the culture decreased to reach a new steady state.

\section{Discussion}

The results of the time-course measurements of glycogen and PHB accumulation in $S$. maxima cultures grown under different conditions are firm evidence of the ability of this micro-organism to synthesize both polymers. However, with the sole exception of mixotrophic growth on acetate, glycogen accumulation was strongly favoured under all growth conditions tested.

During balanced photoautotrophic growth, glycogen was the only carbon storage compound detected, its intracellular concentration being close to that generally reported for cyanobacteria growing under similar conditions (Smith, 1982; Allen, 1984; Shively, 1988). The absence of PHB was surprising because its presence, even at a very low concentration, had seemed to be a constant feature of photoautotrophically grown Spirulina species (Vincenzini et al., 1990). Taking into account the detection limit of the analytical procedure used, the intracellular level of PHB must have been well below $0.005 \%$ of dry wt, that is at least 10 times lower than the mean value found in our previous study. This result strengthens the previous hypothesis that PHB has only a minor role as a storage compound in Spirulina cells growing under balanced photoautotrophic conditions.
When $S$. maxima was grown under mixotrophic conditions, significant accumulation of both glycogen and PHB was observed, thus showing that $S$. maxima possesses the enzymic machinery necessary for the synthesis of PHB. Nevertheless, PHB accumulated to a significant level only if exogenous acetate was available. The positive effect of acetate on PHB accumulation could be directly related to its intracellular conversion into acetyl-CoA at the expense of the free CoA pool, as observed in other cyanobacteria (Ihlenfeldt \& Gibson, 1977): under these conditions the synthesis of lipids is generally stimulated. However, the amount of PHB synthesized during mixotrophic growth represents only about $20 \%$ of the additional cell yield observed in this culture compared to the control. This demonstrates that acetate is utilized not only for PHB formation but also for the synthesis of other cell constituents, as has been suggested by Ihlenfeldt \& Gibson (1977) for Synechococcus and Aphanocapsa strains grown on acetate-enriched media.

When either biosynthetic carbon metabolism or photosynthetic activity were stimulated (cultures grown respectively under nitrogen starvation or shifted to higher light irradiance), the immediate response of $S$. maxima was to enhance the rate of glycogen synthesis so that the net increase of this polymer rose above that of other cell constituents. Since no PHB accumulated under these conditions, it does not seem to act as a true reserve compound for carbon and/or energy. Indeed, among the varied photoautotrophic culture conditions tested, only in two circumstances was any PHB detected: after a prolonged culture period in a mineral medium devoid of either a nitrogen or a phosphorus source. Therefore, those nutrient limitations that had been shown to induce the accumulation of large quantities of PHB in chemoheterotrophic (Dawes \& Senior, 1973; Byrom, 1987; Anderson \& Dawes, 1990) or in photoheterotrophic (Merrick, 1978; Brandl et al., 1991; Liebergesell et al., 1991) micro-organisms had only a minor effect on PHB accumulation in this photoautotrophic cyanobacterium. This distinctive behaviour of Spirulina is most plausibly ascribed to the lack of a complete tricarboxylic acid cycle. In cyanobacteria, this cycle plays an almost exclusively biosynthetic role, being unable to function in efficient substrate oxidation owing both to the absence of some key enzymes of the cycle and to the low activity of the enzymes of the glyoxylate shunt (Smith \& Hoare, 1977; Fay, 1983). PHB synthesis can proceed only if the NADH/NAD ratio and acetyl-CoA concentration are high (Dawes \& Senior, 1973; Anderson \& Dawes, 1990) and it appears therefore that nitrogen starvation in cyanobacteria cannot create conditions favourable to PHB accumulation, since reduced pyridine nucleotides cannot be accumulated as a consequence of substrate 
oxidation, in contrast with what happens in most heterotrophs. On the other hand, some PHB synthesis is permitted under phosphorus starvation, when reducing power may be in excess, because ATP production is known to decrease markedly with the onset of phosphorus limitation (Bottomley \& Stewart, 1976; Konopka \& Schnur, 1981), while the reduction of NADP through non-cyclic photosynthetic electron flow is not inhibited.

On the basis of these observations one can conclude that the role of PHB in cyanobacteria is to provide cells with a mechanism for the removal of excess reducing equivalents which result from a disruption of the balanced formation of ATP and NADPH from photosynthesis.

Research supported by National Research Council of Italy, special project R.A.I.S.A., sub-project no. 4, paper no. 310.

\section{References}

Allen, M. M. (1984). Cyanobacterial cell inclusions. Annual Review of Microbiology 38, 1-25.

Allen, M. M. \& SMith, A. J. (1969). Nitrogen chlorosis in blue-green algae. Archiv für Mikrobiologie 69, 114-120.

ANDERSON, A. J. \& DAwES, E. A. (1990). Occurrence, metabolism, metabolic role, and industrial uses of bacterial polyhydroxyalkanoates. Microbiological Reviews 54, 450-472.

BENNET, A. \& Bogorad, L. (1973). Complementary chromatic adaptation in a filamentous blue-green alga. Journal of Cell Biology 58, 419-435.

Bocci, F., Torzillo, G., Vincenzini, M. \& Materassi, R. (1987). Growth physiology of Spirulina platensis in tubular photobioreactor under natural light. In Algal Biotechnology, pp. 219-228. Edited by T. Stadler, J. Mollion, M. C. Verdus, Y. Karamanos, H. Morvan \& D. Christiaen. London: Elsevier Applied Science.

Bottomley, P. J. \& StewarT, W. D. P. (1976). ATP pools and transients in the blue-green alga, Anabaena cylindrica. Archiv für Mikrobiologie 108, 249-258.

Brandl, H., Gross, R. A., Lenz, R. W., Lloyd, R. \& Fuller, R. C. (1991). The accumulation of poly(3-hydroxyalkanoates) in Rhodobacter sphaeroides. Archives of Microbiology 155, 337-340.

BYrom, D. (1987). Polymer synthesis by microorganisms: technology and economics. Trends in Biotechnology 5, 246-250.

Campbell, J., III, Stevens, S. E., JR \& Balkwill, D. L. (1982). Accumulation of poly- $\beta$-hydroxybutyrate in Spirulina platensis. Journal of Bacteriology 149, 361-363.

Capon, R. J., Dunlop, R. W., Ghisalberti, E. L. \& Jefferies, P. R. (1983). Poly-3-hydroxyalkanoates from marine and freshwater cyanobacteria. Phytochemistry 22, 1181-1184.

CARR, N. G. (1966). The occurrence of poly- $\beta$-hydroxybutyrate in the blue-green alga, Chlorogloea fritschii. Biochimica et Biophysica Acta 120, 308-310.

CARR, N. G. (1988). Nitrogen reserves and dynamic reservoirs in cyanobacteria. In Biochemistry of the Algae and Cyanobacteria, pp. 13-21. Edited by L. J. Rogers \& J. R. Gallon. Oxford: Clarendon Press.

DAwES, E. A. (1986). Microbial energy reserve compounds. In Microbial Energetics, pp. 145-165. Edited by E. A. Dawes. Glasgow: Blackie \& Son.

Dawes, E. A. \& Senior, P. J. (1973). The role and regulation of energy reserve polymers in micro-organisms. Advances in Microbial Physio$\log y$ 10, 135-266.

Dubois, M., Gilles, K. A., Hamilton, J. K., Rebers, P. A. \& Smith, F. (1956). Colorimetric method for determination of sugars and related substances. Analytical Chemistry 28, 350-356.

ERNST, A. \& Böger, P. (1985). Glycogen accumulation and the induction of nitrogenase activity in the heterocyst-forming cyano- bacterium Anabaena variabilis. Journal of General Microbiology 131 , $3147-3153$.

ERnst, A., Kirschenlohr, H., Diez, J. \& BöGER, P. (1984). Glycogen content and nitrogenase activity in Anabaena variabilis. Archives of Microbiology 140, 120-125.

VAN EYKelenBurg, C. (1980). Ecophysiological studies on Spirulina platensis. Effect of temperature, light intensity and nitrate concentration on growth and ultrastructure. Antonie van Leeuwenhoek 46, 113-127.

FAY, P. (1983). The Blue-Greens (Cyanophyta-Cyanobacteria). London: Edward Arnold.

IhLENFELdT, M. J. A. \& Gibson, J. (1977). Acetate uptake by the unicellular cyanobacteria Synechococcus and Aphanocapsa. Archives of Microbiology 113, 231-241.

JENSEN, T. (1985). Cell inclusions in the cyanobacteria. Archiv für Hydrobiologie 71, 33-73.

KarR, D. B., Waters, J. K. \& Emerich, D. W. (1983). Analysis of poly- $\beta$-hydroxybutyrate in Rhizobium japonicum bacteroids by ionexclusion high-pressure liquid chromatography and UV detection. Applied and Environmental Microbiology 46, 1339-1344.

KoNOPKA, A. \& SCHNUR, M. (1981). Biochemical composition and photosynthetic carbon metabolism of nutrient limited cultures of Merismopedia tenuissima (Cyanophyceae). Journal of Phycology 17, 118-122.

LehmaNN, M. \& WöBER, G. (1976). Accumulation, mobilization and turn-over of glycogen in the blue-green bacterium Anacystis nidulans. Archives of Microbiology 111, 93-97.

Liebergesell, M., Hustede, E., Timm, A., Steinbüchel, A., Fuller, R. C., LENZ, R. W. \& SCHLEGEL, H. G. (1991). Formation of poly(3hydroxyalkanoates) by phototrophic and chemolithotrophic bacteria. Archives of Microbiology 155, 415-421.

MERRICK, J. M. (1978). Metabolism of reserve materials. In The Photosynthetic Bacteria, pp. 199-219. Edited by R. K. Clayton \& W. R. Sistrom. New York: Plenum Press.

Parson, T. R. \& Strickland, J. D. H. (1963). Discussion of spectrophotometric determination of marine plant pigments, with revised equations for ascertaining chlorophylls and carotenoids. Journal of Marine Researches 21, 155-163.

Pearce, J. \& Carr, N. G. (1967). The metabolism of acetate by the blue-green algae, Anabaena variabilis and Anacystis nidulans. Journal of General Microbiology 49, 301-313.

Post, A. F. (1987). Transient state characteristics of changes in light conditions for the cyanobacterium Oscillatoria agardhii. II. Dynamics in cellular contents and growth rates. Archives of Microbiology $149,19-23$.

Preiss, J. \& Romeo, T. (1989). Physiology, biochemistry and genetics of bacterial glycogen synthesis. Advances in Microbial Physiology 30 , 183-238.

Rippka, R., Deruelles, J., Waterbury, J. B., Herdman, M. \& StANIER, R. Y. (1979). Generic assignments, strain histories and properties of pure cultures of cyanobacteria. Journal of General Microbiology 111, 1-61.

ShIVELY, J. M. (1988). Inclusions: granules of polyglucose, polyphosphate, and poly- $\beta$-hydroxybutyrate. Methods in Enzymology 167, 195-203.

SMITH, A. J. (1982). Modes of cyanobacterial carbon metabolism. In The Biology of Cyanobacteria, pp. 47-85. Edited by N. G. Carr \& B. A. Whitton. Oxford: Blackwell Scientific Publications.

SMITH, A. J \& HoARE, D. S. (1977). Specialist phototrophs, lithotrophs, and methylotrophs: a unity among a diversity of procaryotes? Bacteriological Reviews 41, 419-448.

Stevens, S. E., JR, Balkwill, D. L. \& Paone, D. A. M. (1981). The effects of nitrogen limitation on the ultrastructure of the cyanobacterium Agmenellum quadruplicatum. Archives of Microbiology 130, 204-212.

Vincenzini, M., Sili, C., Tredici, M. R. \& Materassi, R. (1989). Light dependent nitrogen chlorosis in a heterocystous cyanobacterium. In Nitrogen Fixation with Non-legumes, pp. 71-76. Edited by F. A. Skinner, R. M. Boddey \& I. Fendrik. Dordrecht: Kluwer Academic.

Vincenzini, M., Sili, C., De Philippis, R., Ena, A. \& Materassi, R. (1990). Occurrence of poly- $\beta$-hydroxybutyrate in Spirulina species. Journal of Bacteriology 172, 2791-2792. 